\title{
O DIREITO FUNDAMENTAL À SAÚDE NO ESTADO PANDÊMICO: CONSIDERAÇÕES SOBRE OS LIMITES DA DECIDIBILIDADE JUDICIAL PARA A CONCRETIZAÇÃO DE UM DIREITO SOCIAL EM UM CENÁRIO EXCEPCIONAL.
}

\author{
Rafael da Cunha Pimenta ${ }^{1}$ \\ George Hilton Lemos Neves ${ }^{2}$
}

RESUMO:

A concretização da saúde como direito fundamental social constitucionalmente assegurado é um tema que, há muito tempo, desafia a gestão de políticas públicas por parte do Estado. A crescente judicialização de demandas cujo objeto encerra essa prestação estatal positiva desencadeia a necessidade de um equacionamento entre as infinitas necessidades sociais e os limitados recursos públicos. Recentemente essa questão ganhou nuances dramáticas, em face da pandemia (COVID-19). Nessa perspectiva, pautando-se numa abordagem dedutiva e a partir da análise bibliográfica pertinente, o presente trabalho, de natureza exploratória, pretende discorrer sobre os limites de atuação do Judiciário brasileiro nesse contexto.

Palavras-chaves: Direitos Fundamentais; Saúde; Judicialização; Limites; Pandemia.

\section{THE FUNDAMENTAL RIGHT TO HEALTH IN THE PANDEMIC STATE: CONSIDERATIONS ON THE LIMITS OF JUDICIAL DECISION TO ACHIEVE A SOCIAL RIGHT IN AN EXCEPTIONAL SCENARIO.}

\begin{abstract}
:
The realization of health as a fundamental social right is an issue that has challenged the management of public policies by the State. The increasing judicialization of demands whose object is this positive state provision triggers the need for a balance between the infinite social needs and the limited public resources. This issue has recently taken on dramatic nuances in the face of the pandemic (COVID-19). So, based on a deductive approach and based on bibliographic analysis, the present work, of an exploratory nature, intends to discuss the limits of performance of the Brazilian Judiciary in this context.
\end{abstract}

Keywords: Fundamental Rights; Health; Judicialization; Limits; Pandemic.

\section{INTRODUÇÃO}

Os direitos sociais à saúde são direitos fundamentais que asseguram a existência humana digna e a promoção da justiça social. Em face disso, sua concretização caracteriza-se como assunto de relevante interesse da sociedade, especialmente diante das determinações

\footnotetext{
${ }^{1}$ Mestrando em Direito no Programa de Pós-graduação em Direito na Universidade Federal do Rio Grande do Norte (PPGD-UFRN). Advogado. Servidor Público Federal. E-mail: rafael.pimenta@ufrn.br ${ }^{2}$ Mestrando em Direito no Programa de Pós-graduação em Direito na Universidade Federal do Rio Grande do Norte (PPGD-UFRN). Professor. E-mail: georgehiltonlemosneves@gmail.com
} 
constitucionais relacionadas ao tema, já que tratam de pura manifestação material da liberdade, da igualdade e da dignidade da pessoa humana, integrando assim, um núcleo jurídico essencial de proteção constitucional ao indivíduo.

A vigente Constituição da República preconiza elementos bastante contundentes acerca da indisponibilidade desses direitos sociais, dispondo sobre mecanismos para sua efetiva realização e proteção. Os direitos sociais são afetos à igualdade e almejam garantir aos indivíduos, condições materiais necessárias para a sua sobrevivência digna, consistindo assim, em pressupostos essenciais para o exercício da cidadania. Tais enunciados, portanto, têm o escopo de implementar condições básicas para efetiva fruição das liberdades fundamentais e desenvolvimento humano.

A problemática a ser enfrentada no presente artigo consiste na análise da atuação do Poder Judiciário para a efetivação dos direitos à saúde, tendo como ponderação nuclear a investigação sobre quais seriam os limites das decisões judiciais na busca pela efetivação desse direito social, diante de um cenário pandêmico tal como o decorrente da calamitosa disseminação global da COVID-19.

Como justificativa para a pesquisa proposta, tem-se, essencialmente, a ocorrência de situações bastante comuns nas quais a atuação do Poder Judiciário tem sido decisiva para efetiva concretização do direito constitucional à saúde, circunstância que tem suscitado, por diversas vezes, uma discussão acerca do alcance e da possibilidade de a jurisdição adentrar na seara de atuação dos demais Poderes do Estado, configurando o que se convencionou denominar de ativismo judicial, e que, a depender do contexto em que seja observado, pode vir a ser significativamente nocivo ao Estado Democrático Direito.

A metodologia empregada para presente pesquisa aplicada - fundada em um problema concreto e atual - parte de uma abordagem eminentemente dedutiva, tendo em vista ter como premissa a concepção geral de direitos fundamentais sociais para projetar, em seguida, o foco do estudo no direito à saúde propriamente dito. A natureza da pesquisa converge para uma forma mais especificamente exploratória, pautando-se numa abordagem qualitativa das questões atinentes ao tema. Para tanto, foi empregada a pesquisa bibliográfica como principal procedimento técnico utilizado, a fim de se viabilizar a construção de uma conclusão norteadora para a discussão do problema apresentado.

Em termos estruturais, tentou-se organizar o trabalho de forma concatenada, partindo da abordagem dos aspectos gerais relativos aos direitos sociais e mais propriamente ao direito 


\section{O DIREITO FUNDAMENTAL À SAÚDE NO ESTADO PANDÊMICO: CONSIDERAÇÕES SOBRE OS LIMITES DA DECIDIBILIDADE JUDICIAL PARA A CONCRETIZAÇÃO DE UM DIREITO SOCIAL EM UM CENÁRIO EXCEPCIONAL.}

fundamental à saúde. Em seguida, optou-se por trazer as nuances relacionadas à problemática da efetivação dos desses direitos no cenário brasileiro. Procedeu-se, ainda, à análise sobre os limites da atuação do Poder Judiciário na efetivação do direito social objeto do presente trabalho. Seguiu-se, por fim, para uma análise mais específica, voltada exatamente aos limites da decidibilidade judicial diante de um contexto excepcionalmente atípico, tal como o decorrente da pandemia causadora da COVID-19. Com, escopo conclusivo, então, foram feitas as considerações finais, retomando-se os fundamentos pelos quais se defende a necessidade de uma cautela especial nessa perspectiva concretista da atuação do Poder Judiciário, sobretudo diante de um cenário totalmente atípico.

\section{O DIREITO FUNDAMENTAL À SAÚde E A PROBLEMÁtiCA DA SUA EFETIVAÇÃO NO BRASIL}

Todo ser humano, como ser social ${ }^{3}$, necessita viver com dignidade e cabe ao Estado o protagonismo no cumprimento deste fundamento constitucional tão importante. E nesse contexto, o direito à saúde integra o conteúdo material do próprio direito à vida, sendo essencial a cada cidadão, ficando o Estado incumbido de proporcionar a cada membro da sociedade o garantismo da dignidade da pessoa humana. De acordo com Flumian (2008), o direito à saúde é um direito fundamental e indispensável para uma vida com dignidade, ressaltando-se que os direitos fundamentais e, acima de tudo, a dignidade da pessoa humana a qual o direito à saúde se refere, são indissociáveis, estando no centro o discurso jurídico constitucional.

Para Mariana Figueiredo (2007), a noção de que a saúde constitui um direito humano e fundamental, passível de proteção e tutela pelo Estado é resultado de uma longa evolução na concepção não apenas do direito, mas da própria ideia do que seja a saúde.

O embasamento constitucional da garantia do direito à saúde no Brasil, encontra-se no $\operatorname{artigo~} 6^{\circ}$ da Constituição Federal, cujo rol, elenca os chamados direitos sociais.

\footnotetext{
${ }^{3}$ Sobre o caráter de sociabilidade humana, é relevante atentar para a natureza social do homem como animal político, apontada por Aristóteles, em sua obra "A Política".
} 
Partindo deste pressuposto, o direito à saúde no Brasil, é entendido como um direito que exige do Estado prestações positivas ${ }^{4}$ com o intuito de garantir a efetividade da saúde, sob pena de tornar ineficaz tal direito fundamental. De acordo com o professor José Afonso da Silva (2020), os direitos sociais são prestações positivas proporcionadas pelo Estado, direta ou indiretamente, enunciadas nas normas constitucionais, que possibilitam melhores condições de vida aos mais fracos, tratando-se de direitos que tendem a realizar um equilíbrio concreto das situações sociais desiguais. São, portanto, direitos que se relacionam à igualdade, valendo como pressupostos do gozo das prerrogativas constitucionais individuais, na medida em que criam condições materiais mais propícias ao auferimento de uma igualdade real. Isso, por sua vez, proporciona condições mais compatíveis com o exercício efetivo da liberdade por parte de todos e qualquer cidadão.

Desse modo, o texto consticional consagrou o direito à saúde como elemento fundamental ao cidadão, impondo ao Estado o dever de promovê-lo, por meio de políticas públicas eficazes, de forma a garanti-lo a todo e qualquer cidadão, indistintamente, tendo em vista sempre o objetivo maior de reduzir as desigualdades, na busca constante pela efetiva justiça social.

A realização dessa garantia é uma atribuição, sobretudo, dos Poderes Executivo e Legislativo, que devem determinar a parcela do orçamento público a ser investido no campo da saúde. Entretanto, em virtude da precarização de alguns serviços prestados pelo Estado, é cada vez mais constante a percepção da falta de perspectiva dos cidadãos no que diz respeito à resolução de suas demandas de saúde pela via administrativa, o que tem levado esses cidadãos a buscarem a solução de suas querelas através da judicialização destes pleitos, fato este que tem se tornado cada dia mais comum em virtude do maior acesso à justiça propiciado ao cidadão, advindo do processo de redemocratização o qual o Brasil vem vivenciando.

E essa constatação, inexoravelmente, exige uma ingerência cada vez mais constante do Poder Judiciário nas questões relativas às demandas públicas que envolvem o direito à saúde. E, portanto, se faz necessário que sejam analisados os limites do Poder Judiciário na atuação jurisdicional, bem como as consequências decorrentes do crescimento exponencial da judicialização na seara da saúde.

\footnotetext{
4 A terminologia ora adotada e usualmente empregada para referenciar direitos passíveis de exigibilidade concreta do jurisdicionado em face do Estado é herdada da classificação inaugurada pela teoria dos quatro status, proposta pelo alemão Georg Jellinek, tal como melhor explicitado na obra dos professores Dimitri Dimoulis e Leonardo Martins (2008).
} 


\section{O DIREITO FUNDAMENTAL À SAÚDE NO ESTADO PANDÊMICO: CONSIDERAÇÕES SOBRE OS LIMITES DA DECIDIBILIDADE JUDICIAL PARA A CONCRETIZAÇÃO DE UM DIREITO SOCIAL EM UM CENÁRIO EXCEPCIONAL.}

Criado após a promulgação da Constituição de 1988, o Sistema Único de Saúde permitiu que o acesso à saúde no Brasil - antes fornecido apenas aos trabalhadores vinculados à Previdência Social - fosse realizado de maneira universal, sem qualquer discriminação. Desta forma, a saúde passou a ser um direito de todos os brasileiros, desde a gestação ${ }^{5}$ e estendendo-se ao longo de toda a vida, com foco não apenas na saúde, mas ressaltando a qualidade de vida, numa acepção universal e ampla e irrestrita; inclusive com o fornecimento de medicamentos, insumos e equipamentos a todos quanto necessitem, desde que mediante a prescrição de profissional habilitado. Em assim sendo, todos os brasileiros, amparados em preceitos constitucionais, no que tange aos direitos sociais e fundamentais do cidadão, devem ter acesso à saúde garantido pelo Estado.

Para Maria Paula Dalari Bucci (2017), a despeito do orçamento público limitar a atuação do SUS em sua função originária, o Poder Judiciário, cada vez mais, vem tendo ingerência nas questões relativas à saúde pública, pois mesmo que a atuação nesse campo seja tipicamente atribuída aos Poderes Executivo e Legislativo, o Poder Judiciário não tem como se esquivar de tal mister, haja vista que é função deste, também, a garantia da dignidade humana ${ }^{6}$.

A despeito de existirem vários dispositivos legais relativos ao direito fundamental à saúde, é praticamente impossível que o Estado consiga dar provimento a todas as necessidades da população. E esse aspecto prestacional é bem mais problemático de ser definido em seu conteúdo. Uma das grandes dificuldades disso é o fato de que a Constituição não definiu, explicitamente, em que consiste o objeto do direito à saúde (SARLET, 2007a).

Segundo Hórtis Souza (2010), o conhecimento cada vez mais crescente da população sobre seus direitos, juntamente com a facilidade do acesso ao judiciário nos dias atuais, está, consequentemente, levando as pessoas a judicializarem suas necessidades individuais em busca de serviços e produtos não ofertados ou negados pelo Sistema Único de Saúde.

Entretanto, pautando-se num ensinamento basilar da economia ${ }^{7}$, sabe-se que as necessidades sociais são infinitas, contrapondo-se aos limitados recursos públicos, que são insuficientes para custear de forma plena todas as exigências da população.

\footnotetext{
${ }^{5}$ Não apenas na acepção materna, mas também, tendo em vista a garantia dos direitos do nascituro, instituída no art. $2^{\circ}$ do Código Civil.

${ }^{6}$ Quanto a esse aspecto, também são relevantes os postulados da inafastabilidade da jurisdição (art. $5^{\circ}, \mathrm{XXXV}$, CRFB), bem como a própria garantia de acesso à justiça.

${ }^{7}$ A lei da escassez preconiza que para qualquer tipo de necessidade humana, tem-se uma dicotomia fundamental de mercado que se estabelece entre a infinidade de necessidades e a limitação de recursos.
} 
É diante desse contexto que se torna evidente o conflito entre o princípio do mínimo existencial e o princípio da reserva do possível.

O princípio do mínimo existencial relaciona-se ao fato de o Estado não poder se eximir do cumprimento de seu dever, haja vista que a garantia de um núcleo essencial e basilar de direitos fundamentais está relacionada à garantia de condições dignas de existência e subsistência do indivíduo. Isso implica dizer que é impositiva a determinação de que se garanta pelo menos esse mínimo existencial. Para o professor Daniel Sarmento (2010), a regra do mínimo existencial tem fundamento normativo no princípio da dignidade da pessoa humana, visto que tal princípio apela tanto à liberdade material, como à democracia e ao atendimento integral de necessidades básicas das pessoas.

Por seu turno, o princípio da reserva do possível relaciona-se com os recursos financeiros do Estado, que são finitos e, em assim sendo, a questão orçamentária costuma ser argumento frequentemente utilizado pelo Executivo para justificar sua omissão e limitar sua atuação frente ao cumprimento das demandas judiciais. De acordo com Marrara e Nunes (2010), este princípio está relacionado com a máxima de que ninguém está obrigado ao impossível, nesse caso, aplicada ao Estado no sentido de que este não teria como ser obrigado a concretizar direitos que venham a exigir esforços materiais ou recursos financeiros desproporcionais, que possam vir a impactar significativa e negativamente o orçamento público e que venham a trazer prejuízos a outras políticas públicas.

Essa é a grande problemática inerente ao tema da concretização do direito à saúde, pois este princípio colide com a regra do mínimo existencial, de acordo com o qual o Estado deve garantir aos cidadãos direitos subjetivos mínimos, a fim de viabilizar efetivamente a acesso a padrões básicos de bem-estar.

De acordo com Luís Roberto Barroso (2009), quando se trata de Judicialização, significa dizer que algumas questões de larga repercussão política ou social estão sendo decididas por órgãos do Poder Judiciário, ao invés de estarem sendo tratadas pelas instâncias políticas tradicionais, quais sejam, o Congresso Nacional e o Poder Executivo.

Assim entendendo, pode-se afirmar que a judicialização seria a transferência para a esfera do Poder Judiciário aquelas decisões que, a rigor, seriam de competência do Poder Executivo e Legislativo.

Barroso (2009) ainda esclarece que é necessário diferenciá-la de outro fenômeno, conhecido como ativismo judicial. Para ele, a judicialização e o ativismo judicial são primos, 


\section{O DIREITO FUNDAMENTAL À SAÚDE NO ESTADO PANDÊMICO: CONSIDERAÇÕES SOBRE OS LIMITES DA DECIDIBILIDADE JUDICIAL PARA A CONCRETIZAÇÃO DE UM DIREITO SOCIAL EM UM CENÁRIO EXCEPCIONAL.}

ou seja, vêm da mesma família, frequentam os mesmos lugares, mas não têm as mesmas origens. Não são gerados, a rigor, pelas mesmas causas imediatas.

No contexto brasileiro, a judicialização é um fato, uma circunstância decorrente do modelo constitucional adotado no ordenamento jurídico brasileiro, e não um exercício deliberado de vontade política, onde o Judiciário teve que decidir porque era o que lhe cabia fazer, sem alternativa. Se uma norma constitucional permite que dela se deduza uma pretensão, subjetiva ou objetiva, ao juiz cabe dela conhecer, decidindo a matéria. Já o ativismo judicial é uma atitude, a escolha de um modo específico e proativo de interpretar a Constituição, extrapolando o seu sentido e alcance. Na maioria das vezes ele se instala em situações de retração do Poder Legislativo, de um certo descolamento entre a classe política e a sociedade civil, impedindo que as demandas sociais sejam atendidas de maneira efetiva (BARROSO 2009).

Segundo Wang (2009), a intervenção do Judiciário pode ter uma contribuição muito grande para o alcance da efetivação do direito à saúde. Entretanto, com base nos critérios de necessidade e urgência, o juiz deve buscar tutelar os direitos subjetivos invocados, desde que respeite e não comprometa o direito da coletividade. Desta forma, deve ser entendido que aquilo que pode ser concedido a um indivíduo, não pode ser negado ao demais, e que a prestação da decisão tomada deve ser extensiva a todos com necessidades semelhantes.

Trazer uma argumentação contrária seria defender que o sistema público de saúde no Brasil teria possibilidade de dispor, para todos os seus cidadãos, todos os melhores tratamentos para todos os problemas de saúde existentes, o que não é algo factível, sendo até mesmo irreal, inclusive para os países mais desenvolvidos. Além desse enfoque, é necessário ter um olhar não apenas para quem ganha, mas também para quem pode vir a perder com determinada forma de alocar recursos. Haja vista que a grande quantidade de recursos da saúde que são gastos para cumprir determinadas decisões judiciais não tem como ser alocada sem afetar outras políticas públicas de saúde que, por sua vez, também protegem o que seria o mínimo existencial de outros cidadãos (WANG, 2009).

Percebe-se, assim, que a individualização da concessão de um direito coletivo consiste, de certa forma, em uma disputa entre o interesse social e o interesse individual. E o que se tem verificado, na maioria das vezes, são decisões judiciais que substituem a tutela de cognição pela via sumária, unilateral e satisfativa, fazendo vir à tona o grande poder que a jurisdição tem na questão relativa à efetivação dos direitos à saúde. Em assim sendo, é de 
suma importância realizar uma análise de quais seriam as limitações da atuação do Poder Judiciário nesse contexto.

\section{A ATUAÇÃO DO PODER JUDICIÁRIO BRASILEIRO NAS DEMANDAS RELACIONADAS À SAÚDE}

O sistema de saúde atual no Brasil apresenta uma séria instabilidade e ameaça ruir em decorrência dos excessos de decisões sensíveis sobre o tema, as quais fazem com que a Administração Pública seja obrigada a custear tratamentos, por vezes, irrazoáveis. Diante disso, faz-se necessário que a atuação do Judiciário seja analisada levando-se em consideração tanto os aspectos práticos quanto os aspectos teóricos das decisões, em virtude das consequências sociais e políticas decorrentes da judicialização da saúde no Brasil.

Trata-se de uma questão de grande complexidade e o papel do Poder judiciário tem sido bastante relevante e decisivo nesse contexto. Desta forma, é mister que haja uma delimitação da atuação judicial a fim de que seja contemplada a harmonia entre os Poderes do Estado, bem como o respeito aos direitos fundamentais e a igualdade substancial entre todos os cidadãos que compõem a coletividade.

Nessa perspectiva, há aspectos que se relacionam a quais deveriam ser as limitações da atuação judicial no que diz respeito à efetivação dos direitos à saúde, a saber, a adequação ao princípio da reserva do possível, a observância ao princípio da separação dos poderes, e o respeito à discricionariedade administrativa.

No que diz respeito ao princípio da reserva do possível, é interessante que seja feita uma análise levando-se em consideração duas vertentes, quais sejam, a reserva do possível jurídica e a reserva do possível fática. Pode-se dizer que a reserva do possível jurídica está associada à falta de autorização orçamentária para o fomento de determinada despesa, já a reserva do possível fática está relacionada à exaustão orçamentária.

De acordo com Salazar (2009), a reserva do possível jurídica, ou inexistência de previsão orçamentária, é tida como um óbice a ser transposto, haja vista que o entrave na falta de orçamento é algo muito específico e, a despeito de a autorização contemplada em lei orçamentária anual ser estritamente necessária para a concretização dos gastos públicos, conforme preceitua o artigo 167, inciso II da Constituição da República, não deve ser motivo 


\section{O DIREITO FUNDAMENTAL À SAÚDE NO ESTADO PANDÊMICO: CONSIDERAÇÕES SOBRE OS LIMITES DA DECIDIBILIDADE JUDICIAL PARA A CONCRETIZAÇÃO DE UM DIREITO SOCIAL EM UM CENÁRIO EXCEPCIONAL.}

de vedação ao Poder judiciário, impedindo-o de proferir decisões que visem garantir a efetivação do direito à saúde em virtude da ausência de previsão orçamentária dessa despesa.

Nesses casos, existe uma colisão de normas constitucionais, onde o princípio da ponderação deve ser colocado em prática, indicando que o direito com mais relevância deve preponderar. Na questão ora apreciada, a colisão entre o direito fundamental à saúde, diretamente associado à garantia do bem maior do ser humano, qual seja, a vida, versus a necessidade de legalização da despesa, a prevalência deve ser direcionada à garantia do direito fundamental à saúde, pois caso a efetivação do direito à saúde ficasse sempre subordinada à reserva orçamentária, incorreria-se na impossibilidade da concretização de uma proteção judicial efetiva dos direitos sociais. Por sua vez, a reserva do possível fática consiste na inexistência de recursos públicos suficientes para o cumprimento da prestação social. Em situações como essa, entende-se que há uma limitação material, uma real escassez de recursos, potencialmente capaz de impedir a realização dos direitos fundamentais.

Entretanto, cabe ressaltar que no Brasil, de acordo com Torres (2009), a reserva do possível fática acaba, na prática, não sendo uma limitação, haja vista que existe a possibilidade de adjudicação de direitos prestacionais sempre que houver disponibilidade financeira nos cofres públicos, ainda que esses recursos estivessem sido, a priori, destinado a outras dotações orçamentárias. E, como o dinheiro público é inesgotável, uma vez que o Estado sempre pode extrair mais recursos da sociedade, entende-se, assim, que há permanentemente a possibilidade fática de garantia de direitos, inclusive pela via do sequestro da renda pública. Desta forma, pode-se dizer, em outras palavras, que da forma como essa questão vem sendo conduzida no Brasil, é faticamente impossível entender a tal reserva do possível fática como uma limitação da atuação judicial na efetivação do direito à saúde.

Diante disso, de acordo com Sarlet e Figueiredo (2007), é importante que o princípio da reserva do possível seja entendido de uma forma mais ampla, primeiramente, entendendo as suas duas espécies, quais sejam, a jurídica e a fática, como sendo dimensões e, correlacioná-las a uma outra dimensão que leve em consideração a razoabilidade e a proporcionalidade da prestação, sendo que essas considerações devem sempre servir de critério e limite para a decisão judicial.

No que concerne à separação de poderes, segundo Bester (2005), ela existe, primordialmente, para limitar o Poder em relação aos direitos dos cidadãos. Como é muito difícil que o poder exercido de modo unitário respeite todos os direitos dos cidadãos, seria, 
então, a separação dos Poderes o pré-requisito para a garantia do respeito aos direitos fundamentais.

De acordo com Danielli (2018), o princípio da tripartição de poderes tem como objetivo o equilíbrio entre os poderes, a fim de se evitar a concentração de poder. Desta forma, estabeleceu-se que o Executivo colocaria em prática as leis criadas ou modificadas pelo Legislativo, enquanto o Judiciário, como órgão neutro, seria o responsável pelo julgamento de demandas decorrentes do não cumprimento dessas leis. Essa separação de poderes permitiu a limitação do poder político, favorecendo a abstenção dos Estados nos direitos de liberdade e demais aspectos da vida social da população. Com o advento do Estado Democrático de Direito houve um fortalecimento do Judiciário, que passou a executar as ações e omissões do Executivo e Legislativo, com a finalidade de assegurar os direitos fundamentais e sociais dos cidadãos.

Entretanto, de acordo com Viana (2017), não deve ser conferido ao Judiciário o direito de apoderar-se das iniciativas típicas do Poder Executivo, a quem compete realizar políticas públicas; ou do Poder Legislativo, a quem cumpre editar comandos normativos vinculativos para esse objetivo. A atuação do Poder Judiciário deve consistir em, após ser provocado por quem bater às suas portas, analisar se estão sendo cumpridos os preceitos e imperativos constitucionais específicos sobre a temática em pauta. E, em caso negativo, ou seja, no caso em que se constate a omissão dos demais poderes, do Legislativo em legislar, e do Executivo em realizar, aí sim compete ao Judiciário determinar que se dê vida ao programa Constitucional, e, assim o fazendo, contribuir para a plena materialização do Estado Democrático de Direito.

Contudo, não se está aqui a defender uma supremacia do Poder Judiciário, muito menos a ausência de limites em sua atuação. Os limites devem sempre existir, e toda forma de excesso de poder, seja na concentração formal, seja no modo de exercício, revela-se como sendo antidemocrático.

Tampouco se está a dizer que o Judiciário seja a solução para todos os problemas sociais, com certeza não é. O que se procura defender é que o Judiciário, efetivamente, cumpra seu papel e sua função social, contribuindo para emergência de um real Estado Democrático de Direito, e não ser um Poder meramente formal e encolhido diante de interesses pontuais. 


\section{O DIREITO FUNDAMENTAL À SAÚDE NO ESTADO PANDÊMICO: CONSIDERAÇÕES SOBRE OS LIMITES DA DECIDIBILIDADE JUDICIAL PARA A CONCRETIZAÇÃO DE UM DIREITO SOCIAL EM UM CENÁRIO EXCEPCIONAL.}

Mas isso não deve ser confundido, de maneira alguma, com a prática do ativismo judicial, pois cabe relembrar que, na democracia constitucional brasileira, o Legislativo e, em certa medida, o próprio Executivo, são os poderes que possuem legitimidade para realizar opções políticas que orientem os rumos de uma comunidade, haja vista que são compostos por representantes eleitos pelo povo para essa finalidade. Já o Judiciário, por sua vez, é formado por juízes que são investidos em seus cargos pela via burocrática, mediante um concurso que afere conhecimento técnico e não representatividade popular, para o exercício da jurisdição. Não cabendo a esse poder realizar juízo político visto que não possui legitimidade para tanto e porque a função que exerce não é a legislativa, mas a jurisdicional; pois não criam lei, apenas devem aplicar a lei criada pelo órgão constitucionalmente competente para tanto, sempre, é claro, numa atividade interpretativa inerente que enriquece o produto interpretado, a saber, o texto normativo (ABBOUD; SANTOS e FERNANDES, 2020).

No que diz respeito à limitação relativa à discricionariedade administrativa, pode-se dizer que, de certa forma, também está relacionada ao princípio da separação dos poderes e consiste na liberdade do administrador em colocar em prática uma apreciação subjetiva de acordo com as circunstâncias concretas de cada caso específico, através de análise criteriosa de um mérito administrativo, com o intuito de obter subsídios que fundamentem uma decisão relativa ao momento oportuno para a realização de um ato administrativo, bem como a escolha de determinada conduta que seja adequada ao caso em análise.

Segundo Salazar (2009), a discricionariedade seria a margem de liberdade que é atribuída ao administrador, através de determinadas normas que o possibilitem a escolher, de acordo com critérios plausíveis de razoabilidade qual deveria ser a solução mais adequada à satisfação da finalidade legal estabelecida.

Cumpre destacar, portanto, que a atuação do Poder Judiciário em questões que interferem no campo das políticas públicas deverá ser sempre subsidiária, haja vista que, a despeito da possibilidade de sua interferência para a boa fruição dos direitos fundamentais, esta não é a sua função primordial.

De acordo com Canela Júnior (2011), o Poder Judiciário deve ter uma atribuição constitucional residual na seara das políticas públicas. Isto significa que a jurisdição não pode intervir indistintamente nas políticas públicas desenvolvidas pelos demais poderes. Isso somente deve acontecer no caso de omissão ou de conflito com os núcleos constitucionais. 
Dentro desse contexto, entende-se que a atuação do Poder Judiciário deverá estar limitada ao princípio da proporcionalidade. Nos casos em que o Poder Judiciário esteja autorizado a examinar os meios utilizados e os fins a serem alcançados pelas demais formas de expressão do poder estatal no desenvolvimento das políticas públicas, não poderá estabelecer soluções iníquas, desproporcionais ou desarrazoadas para o caso concreto. Visto que também desenvolve políticas públicas por meio de suas decisões, o Poder Judiciário haverá de harmonizar-se com os critérios de justiça, de proporcionalidade, de razoabilidade que informam o ordenamento jurídico (CANELA JÚNIOR, 2011).

De acordo com Picardi (2008), um outro fator que impõe limite à atuação do Judiciário, diz respeito às fendas do ordenamento jurídico. Estas não se confundem com as lacunas da lei, pois o juiz pode colmatar as lacunas, mas não tem como vedar as fendas, haja vista que essas exigem uma ação do legislador. As lacunas são tratadas como um complexo de técnicas legislativas, por meio das quais se acaba por delegar ao juiz escolhas que o legislador não pode ou não quer fazer. Mas nos casos fendas o legislador constitucional brasileiro criou procedimentos específicos a serem trabalhados, a saber, a Ação Direta de Inconstitucionalidade por Omissão e o Mandado de Injunção.

Desta forma, a atuação do judiciário encontra limites nas fendas do sistema jurídico, pois não pode supri-las através do ativismo judicial, haja vista que essa atitude foge às amarras legais e normativas, porque se cria políticas públicas de saúde e determina sua implementação pela Administração Pública e, ainda, faz aplicação direta da Constituição a situações que não foram expressamente contempladas em seu texto, criando-se uma normatividade concorrente.

Assim, a adoção do ativismo judicial é ilegítima, notadamente quando interfere na alocação de recursos públicos, prejudicando todo o planejamento da Administração Pública e desrespeitando a lei orçamentária (PICARDI 2008).

Entende-se, portanto, que o Judiciário deve observar alguns limites na efetivação do direito à saúde, os quais devem se conter dentro do conteúdo de cada processo, conforme um juízo de ponderação entre o que se pleiteia e o que é realmente possível conceder, sem comprometer os interesses coletivos, respeitando as políticas públicas vigentes e o princípio da reserva do possível, a discricionariedade da Administração Pública e a separação dos poderes. 


\section{OS LIMITES DA DECIDIBILIDADE JUDICIAL PARA A CONCRETIZAÇÃO DOS DIREITOS À SAÚDE EM UM CENÁRIO PANDÊMICO}

O tema da atuação do Poder Judiciário na concretização do direito fundamental à saúde, de fato, é um campo extremamente fértil para discussões nas mais diversas searas da própria teoria jurídica. Isso porque, para além da materialização efetiva dos direitos fundamentais, envolve aspectos de extrema relevância para o Estado, atinentes à orçamento público; responsabilidade fiscal; separação dos poderes da República; políticas públicas etc.

Essa relevância temática do presente objeto de estudo é corroborada pela considerável quantidade de produções acadêmicas envolvendo a questão e, sobretudo, exatamente pelas decisões judiciais diariamente prolatadas nessa perspectiva concretista da atuação do Poder Judiciário para a efetivação dos direitos sociais. O fato é que com tudo o que já foi produzido, ainda há consideráveis indefiniçõos sobre o direito social à saúde que autorizam e justificam esse esforço acadêmico.

Ademais, se em um cenário habitual e tido como normal, a ponderação (ALEXY, 2008) entre proposições normativas de ordem constitucional demanda, a rigor, uma análise detida e criteriosa por parte dos operadores do Direito, de maneira muito mais enfática, tem-se a imperiosa necessidade de adequar toda essa sistemática de concretização em face de um contexto totalmente atípico e sem precedentes na era Contemporânea, tal como o que emerge da disseminação global do vírus Sars-CoV-2, causador da COVID-19 e responsável pela pandemia que aflige o mundo há mais de 1 (um) ano.

A atuação do Poder Judiciário nessa vertente situacional parece precisar se revestir de uma perspectiva eminentemente garantista das necessidades básicas dos indivíduos contra eventuais arbitrariedades e possíveis abusos estatais ${ }^{8}$, sem que isso, contudo, possa desencadear qualquer tipo de instabilidade institucional, uma vez que toda decisão tendente a assegurar algum tipo de prestação voltada à saúde de um determinado indivíduo passa a apresentar contornos muito mais limítrofes - e talvez dramáticos - em um cenário estritamente atípico.

\footnotetext{
${ }^{8}$ Não seria razoável, ainda que em se tratando de um contexto reconhecidamente excepcional, que se cogitasse a inobservância do princípio da vedação ao retrocesso social, de forma a desconsiderar conquistas historicamente construídas e derivadas de tanto esforço da sociedade.
} 
Se o ajuizamento de demanda tendente a assegurar uma prestação material no âmbito da saúde de um jurisdicionado, via de regra, é tratado pelos Juízes com um hard case exatamente por demandar uma ponderação de valores e envolver questões sensíveis para o Estado - com muito mais propriedade estar-se-á diante de um super hard case ao tentar dirimir um conflito dessa natureza em um contexto pandêmico, para o qual nenhuma nação do mundo estava preparada.

O que se impõe, portanto, é a necessidade de tentar equacionar os limites dessa potencial concretização do direito constitucional à saúde com o estado de emergência de saúde pública de importância internacional (declarado pela Organização Mundial da Saúde OMS), ao qual todos, forçada e invariavelmente, foram submetidos. Contudo, a efetivação dessa conformação pode representar um dos maiores desafios atuais para a jurisdição, sobretudo num contexto em que todo o Estado - e todos, ou quase todos, os Estados soberanos do globo terrestre - ainda se revela $(m)$ totalmente impotente(s) diante desse inimigo invisível e avassalador.

O fato é que, desde meados de março de 2020, o mundo se deparou com uma situação por poucos imaginada, a partir da qual as fronteiras territoriais de toda e qualquer nação independente - por mais fortalecidas que fossem - pouco importavam diante do franco acesso às enormes porteiras microbiológicas que cada indivíduo representava. O mundo, rapidamente, passou a ser um grande celeiro da doença (AGAMBEM, 2020).

A rapidez voraz com que o vírus se disseminava e os impensáveis níveis de contágio constatados desde os estudos iniciais, em pouco tempo, ocasionaram o colapso dos sistemas políticos e econômicos mundiais, "contaminando" não apenas a indústria da saúde, tal como propôs o professor Ahmed Sameer El Khatib (2020).

Não importava o tamanho ou a riqueza do Estado-nação, todos foram reduzidos a núcleos infectados e/ou infectantes. Do mesmo modo, não fazia diferença alguma se o indivíduo era negro ou branco; rico ou pobre; mulher ou homem. Todos estavam igualmente sujeitos à patologia e a suas trágicas consequências. Nesse aspecto, o mundo se tornou um espaço sem fronteiras e a pandemia igualou a todos em uma, talvez nunca antes vista, situação de relativa isonomia material em face de um inimigo comum, desconhecido, agressivo e mortal.

Não seria, portanto, lógica ou socialmente aceitável uma atuação do Poder Judiciário no sentido de impor algum tipo de garantia constitucional a determinado indivíduo, em 


\section{O DIREITO FUNDAMENTAL À SAÚDE NO ESTADO PANDÊMICO: CONSIDERAÇÕES SOBRE OS LIMITES DA DECIDIBILIDADE JUDICIAL PARA A CONCRETIZAÇÃO DE UM DIREITO SOCIAL EM UM CENÁRIO EXCEPCIONAL.}

detrimento de toda uma coletividade em idêntica situação jurídica, diante de um contexto no qual nenhum cidadão teria, sequer, a certeza da existência de leitos aptos a uma internação hospitalar, se necessária fosse. Não seria, portanto, uma hipótese de não prestação de um direito fundamental. O caso encerra um contexto de demandas de saúde estritamente similares - ou quiçá, idênticas - imersas em um cenário de total insuficiência de recursos, em um colapso concomitante dos sistemas de saúde mundiais.

Para analisar essa perspectiva estatal prestacionista, sobretudo em um cenário de crise (generalizada), parece salutar partir da acepção una do Estado, cuja legitimação política decorre de um manancial também singular, insculpido no parágrafo único do $\operatorname{art.} 1^{\circ}$ da Constituição da República. Afinal, é do povo todo o poder que perfaz um Estado e é em seu nome que esse poder deve ser exercido, tal como há tempos se depreende das lições do abade Sieyés (1988).

Com o escopo de melhor sistematizar essa estruturação, surge a clássica teoria de um poder tripartido, pautada na máxima de dividir e especializar para melhor organizar. Evidentemente, numa concepção contemporânea, a tripartição dos poderes do Estado já não pode ser compreendida sob um viés eminentemente estático e puramente formal, pois para além das atribuições típicas e atípicas de cada faceta desse poder, é imprescindível destacar o regime de freios e contrapesos ${ }^{9}$ que constitui um sistema de limitação e regulação recíproca entre Executivo, Legislativo e Judiciário.

Cada um desses núcleos políticos de poder estatal apresenta peculiaridades relevantes que os tornam mais compatíveis com suas atribuições constitucionais precípuas. Disso decorrem alguns fatores que, para o objeto do presente estudo, acabam por favorecer ou, ao menos, facilitar - um certo protagonismo do Poder Judiciário para a tentativa de um gerenciamento mais urgente de cenários de instabilidade, senão veja-se.

O Poder Legislativo, em sua típica atuação legiferante, é regido por um procedimento burocrático ${ }^{10} \mathrm{e}$, por vezes, extremamente moroso para a produção normativa,

\footnotetext{
${ }^{9} \mathrm{O}$ sistema conhecido como checks and balances viabiliza uma distribuição dinâmica da responsabilidade sobre a regulação da atuação do Estado nas suas mais diversas searas. De forma coordenada - e pensando-se um modelo ideal - esse mecanismo seria apto a otimizar as funções estatais, tendo em vista que todos colaboram e fiscalizam a atuação dos demais envolvidos. A rigor, contudo, tem se mostrado mais propriamente um fundamento dogmático para a invasão indevida de competências constitucionais.

${ }^{10}$ Para revestir a produção legislativa do caráter de segurança que se espera em um Estado Democrático de Direito, a Constituição estabelece um procedimento solene - art. 59 e seguintes da Constituição - para viabilizar o ingresso de uma norma no ordenamento pátrio.
} 
característica incompatível com a celeridade pensada para um cenário de urgência excepcional que exige respostas rápidas.

O Poder Executivo, em face do princípio da legalidade estrita (art. 37, CRFB), tem, em tese, uma atuação prática bastante limitada, sobretudo em face das restrições orçamentárias cominadas por lei. Ademais, o atual momento político-partidário brasileiro é nítida e extremamente instável, circunstância que parece dificultar, ainda mais, a gestão, a coordenação e a própria atuação administrativa para o enfrentamento da pandemia.

O Poder Judiciário, por seu turno, pautando-se num arcabouço constitucional repleto de direitos fundamentais, bem com diante da garantia de inafastabilidade da jurisdição e com a possibilidade concreta - facultada pela sistemática processual civil - da prolação de decisões de mérito em regime liminar (evidentemente, com a observância dos requisitos legais), parece apto a assumir uma posição de destaque na gestão dessa crise sanitária.

Ocorre, todavia, que, no exercício da função judicante, a despeito dessa aparente facilidade - e permissibilidade - para solucionar os problemas submetidos a uma apreciação casuística, é imprescindível que haja sensibilidade dos magistrados no sentido de reconhecer a inédita excepcionalidade conjuntural a que estão submetidos. E essa constatação deve ocorrer com muito mais ênfase no âmbito das demandas de saúde.

Evidentemente, tal percepção não deve decorrer exclusivamente da crítica pessoal ou da autoanálise de cada agente julgador. Na verdade, é preciso partir de um elemento basilar de natureza cogente, consubstanciado na existência de limites legítimos aos próprios direitos fundamentais.

Para os professores Leonardo Martins e Dimitri Dimoulis (2008), os limites dos direitos fundamentais se manifestam de diferentes modos e com distintos níveis de restringibilidade, a depender da forma como são elencados no texto constitucional. No caso do direito fundamental à saúde, tem-se um conceito amplo, mas determinado ${ }^{11}$, não havendo, pois, que se falar em reserva legal para sua concretização. De todo modo, ainda assim, não se cogita a existência de um direito fundamental absoluto.

Restaria, nesse caso, o recurso ao critério da proporcionalidade como medida para estabelecer os limites desse direito fundamental, sobretudo diante de situações colidentes envolvendo outros direitos fundamentais. A análise, portanto, deve ser fundada no binômio

${ }^{11}$ Por maior que seja a amplitude do conceito de saúde, não há que se falar em conceito jurídico indeterminado e/ou carente de concretização por lei posterior. A abrangência do conteúdo material não se confunde com vagueza de sentido ou insuficiência de delimitação jurídica. 
necessidade-adequação. E mais: deve ser razoável, sob pena de imputar a uma das partes um ônus abusivo incompatível com a pretensão de isonomia relacional.

Deve-se, então, sopesar os direitos fundamentais envolvidos, a fim de perquirir, diante de um caso concreto, qual deles deve prevalecer sobre o outro, casuisticamente.

E diante de um cenário pandêmico, todas essas considerações são, ainda, permeadas por uma catastrófica crise epidemiológica, na qual os direitos fundamentais revestem-se de uma condição ainda mais peculiar, podendo ser, inclusive, relativizados ${ }^{12}$.

Nesse contexto, portanto, o ajuizamento de uma demanda de saúde cujo pedido liminar seja direcionado à garantia de uma internação hospitalar para determinado paciente infectado pela COVID-19 parece algo realmente temerário. Isso porque, reflexamente, estarse-á diante de uma colisão de direitos iguais, entre indivíduos nas mesmas situações jurídicas.

Veja-se, ainda, que tal colisão não é simplesmente um embate entre 2 (dois) postulados constitucionais; ou uma celeuma envolvendo 2 (dois) polos processuais. Na verdade, há em qualquer contexto vislumbrado nessa perspectiva um componente efetivamente multidimensional, porque envolve diretamente toda uma coletividade e uma ampla gama de direitos. E esses processos de natureza estrutural carecem de uma análise mais criteriosa (CORTÊS, 2020).

O ponto crucial, portanto, não é, simplesmente, a garantia do direito à saúde, mas a preservação da isonomia que permeia toda a cadeia de sustentação dos direitos fundamentais, bem como a imperativa necessidade de observância da dignidade da pessoa humana, fundamento do próprio Estado Democrático de Direito, a qual, ainda, que concebida indevidamente - como um enunciado sobremodo abstrato, é inegável que se trata de um valor dos mais caros e extremamente necessário em um contexto de crise como o atualmente vivenciado.

\section{CONSIDERAÇÕES FINAIS}

\footnotetext{
${ }^{12}$ Exemplificativamente, veja-se que em situações excepcionais, tais como no Estado de Defesa ou Estado de Sítio, são adotadas medidas igualmente atípicas, dentre as quais a restrição de direitos fundamentais (arts. 136 e 137 da Constituição da República). A emergência mundial de saúde pública causada pela COVID-19, embora não tenha ensejado a decretação de um Estado de Exceção propriamente dito, inspira uma atenção especial por parte de todos os envolvidos.
} 
Todo esse contexto social atípico exige, naturalmente, um tratamento igualmente peculiar por parte dos Estados, capaz de considerar, de fato, as nuances e vicissitudes impostas pela situação que, concretamente, atingiu o mundo, de forma totalmente inesperada.

E nesse cenário pandêmico é oportuno ressaltar a necessidade de um manejo cuidadoso de todas as facetas nas quais repercute a atual crise epidemiológica, sobretudo porque espera-se dos Estados uma tutela minimamente eficiente das necessidades dos indivíduos.

O processo de judicialização deve ser, de fato, visto como algo efetivamente natural (CORTÊS, 2020), principalmente em face do arquétipo jurídico-constitucional que institui um rol bastante pródigo de direitos e garantias aos jurisdicionados. Todavia, esse amparo normativo ao cidadão não pode ensejar uma fragilização das sólidas estruturas sobre as quais se assenta o Estado Democrático de Direito.

E como naturalmente ocorreria, a pandemia também "contaminou" o Poder Judiciário, no sentido de que, como núcleo estatal detentor do poder - de definitividade - da jurisdição, passou a receber, cotidianamente, em todo o território nacional, demandas com causas de pedir diretamente atreladas à COVID-19. Foram submetidas à apreciação do Judiciário ações revisionais de $\operatorname{contratos}^{13}$; discussões acerca de conflitos normativos surgidos entre decretos publicados por entes federativos distintos ${ }^{14}$; questionamentos sobre a permissibilidade de funcionamento ou não de estabelecimentos comerciais; insurgências quanto a restrições à liberdade de locomoção, enfim, provocou-se o posicionamento do Estado-Juiz sobre questões sensíveis atinentes à preservação de direitos fundamentais durante esse momento excepcional.

Ocorre que essas questões ora suscitadas apresentam uma carga política bastante considerável e, embora a Ciência do Direito, necessariamente se relacione intrinsecamente com a Ciência Política, em termos pragmáticos é essencial que se afaste da forma mais contundente possível o risco de politização da Justiça (BARROSO, 2009). O juiz, portanto, não pode perder de vista que sua atuação deve ser respaldada inicialmente pela Constituição, sem, ainda, desconsiderar o pressuposto segundo o qual as leis infraconstitucionais também

${ }^{13}$ A faceta econômica da crise redundou num inesperado desequilíbrio financeiro orçamentário em muitos contratos em vigor, tais como os pactos de locação de imóveis comerciais, por exemplo.

${ }^{14}$ Por meio da Ação Direta de Inconstitucionalidade (ADI) nº 6341, o Supremo Tribunal Federal (STF) ratificou a competência concorrente dos entes federativos para tratar de questões atinentes ao enfrentamento da pandemia. Reflexamente, contudo, tal medida parece ter revelado uma ausência de critérios mais objetivos para determinar o possível alcance da esfera dinâmica de competência de cada ente, aspecto que redundou em vários conflitos normativos, sobretudo entre Estados e Municípios. 


\section{O DIREITO FUNDAMENTAL À SAÚDE NO ESTADO PANDÊMICO: CONSIDERAÇÕES SOBRE OS LIMITES DA DECIDIBILIDADE JUDICIAL PARA A CONCRETIZAÇÃO DE UM DIREITO SOCIAL EM UM CENÁRIO EXCEPCIONAL.}

integram o ordenamento e gozam de presunção de legitimidade e validade. Ademais, como agentes dotados de independência funcional e investidos na função judicante por meio de processo distinto da corrida eleitoral, são precisam - e mais propriamente, não podem - se preocupar com a necessidade de ser populistas, uma vez que, em prol da garantia de proteção - técnico-jurídica - dos direitos fundamentais, podem ser chamados a agir de modo contramajoritário.

Entretanto, no afã de contribuir de forma concreta com a estabilização de uma situação carente de respostas rápidas e com o abrandamento do caos instalado no território nacional - e mundial - em face da pandemia, o Judiciário, em determinadas circunstâncias, parece ter sido conduzido a atuações extremamente práticas, mas com um significativo potencial de instabilidade orgânica do próprio Estado, como nos casos de imposições que comprometem de forma mais contundente planos, previsões e leis orçamentárias.

Vale salientar que não houve, até o presente momento, decretação formal de Estado de Exceção nos termos constitucionais. Logo, é a proporcionalidade que deve permear a atuação jurisdicional nos hard cases, sobretudo naqueles mais peculiares.

Isso porque todo o arcabouço teórico de organização estatal e de proteção aos indivíduos é fundado na existência de limites.

Assim, os movimentos constitucionais ${ }^{15}$, sobretudo após a II Guerra Mundial, são fundados, essencialmente, limitação do poder estatal; os poderes estruturantes do Estado também são reciprocamente limitados (checks and balances); igualmente, os direitos e garantias fundamentais - como não absolutos - devem apresentar limites; e, em última análise, a própria possibilidade de limitação desses direitos deve possuir limites ${ }^{16}$.

Em um Estado Democrático de Direito, portanto, não haveria espaço para um aproveitamento ilegítimo de um contexto excepcional - seja por parte de particulares e/ou do próprio Estado - para que fossem realizadas coletas ilícitas de dados pessoais ${ }^{17}$; restrições

\footnotetext{
15 Expressão cunhada pelo professor Canotilho (2003) para melhor representar a diversidade de "constitucionalismos" existentes nos ordenamentos jurídicos ao redor do mundo e ao longo das eras.

${ }^{16}$ A teoria do limite dos limites, propugnada pela doutrina alemã, aborda um viés de concessões e restrições recíprocas cuja finalidade última é estabelecer um equilíbrio dinâmico na relação entre os cidadãos, estabelecendo um núcleo essencial de proteção jurídica fundamental, irredutível, inegociável e inafastável. (DIMOULIS; MARTINS, 2008)

17 O próprio STF, ao analisar o conteúdo da Medida Provisória (MP) $n^{\circ}$ 954/2020, que previa o compartilhamento de dados de usuários de sistemas de telefonia com o Instituto Brasileiro de Geografia e Estatística (IBGE), para produção de estatística oficial durante a pandemia COVID-19, assentou a inconstitucionalidade da norma.
} 
injustificadas a direitos civis básicos ${ }^{18}$; relativização à autonomia individual ou mesmo para a não concretização de direitos sociais. Todavia, circunstâncias excepcionais exigem medidas extraordinárias e, a despeito da não declaração formal do Estado de Exceção, a relativização temporária e excepcional de determinados direitos fundamentais, pode ser justificada pelo manejo técnico e bem fundamentado da proporcionalidade.

Todas essas ponderações podem perfeitamente ser aplicadas ao contexto da concretização do direito fundamental à saúde. Isso porque, numa conjuntura pandêmica, a nenhum agente poderá ser concedida uma legitimação formal - por mais poder estatal que ostente - para deliberar e determinar sobre a quais pessoas deve ser dada a chance de lutar pela vida. Afinal, todos são iguais perante a Lei.

\section{REFERÊNCIAS}

ABBOUD, G.; SANTOS, M. B. de A.; FERNANDES, R. Y. Atuação do STF na pandemia do Covid-19. Fine line entre aplicação da Constituição Federal e ativismo judicial. Revista dos Tribunais. São Paulo: 2020. Disponível em: https://dspace.almg.gov.br/handle/11037/38657. Acesso em: 30 out. 2020.

AGAMBEM, Giorgio. Reflexões sobre a peste: ensaios em tempos de pandemia. Tradução de Isabella Marcatti. São Paulo: Editorial Boitempo, 2020.

ALEXY, R.. Teoria dos Direitos Fundamentais. Tradução de Virgílio Afonso da. Silva. São Paulo: Malheiros Editores, 2008.

BARROSO, L. R. Judicialização, Ativismo Judicial e Legitimidade Democrática. Anuário Iberoamericano de Justicia Constitucional, n. 13, 2009.

BESTER, G. M.. Direito Constitucional: fundamentos teóricos. Vol I, São Paulo: Manole, 2005.

BRASIL. Constituição (1988). Constituição da República Federativa do Brasil. Brasília, DF: Senado Federal, 2015.

BUCCI, M. P. D. (Coord.); DUARTE, C. S. (Coord.). A judicialização da Saúde: A visão do poder executivo. São Paulo: Ed. Saraiva. 2017.

CANELA JÚNIOR, O.. Controle Judicial das Políticas Públicas. São Paulo: Saraiva, 2011.

\footnotetext{
${ }^{18}$ Muitos Estados e Municípios da Federação determinaram medidas robustas de isolamento social, chegando a decretar toques de recolher e estabelecer um regime de lockdown.
} 
CANOTILHO, J. J. Gomes. Direito constitucional e teoria da constituição. 7. ed. Coimbra: Almedina, 2003.

CÔRTES, Osmar Mendes Paixão. Covid/19, Processo Estrutural e Ativismo Judicial.

Migalhas, Ribeirão Preto, p. 1-16,14 abr. 2020. Disponível em:

https://www.migalhas.com.br/arquivos/2020/4/DC447C1221B26F_COVIDPROCESSOSEST RUTURAISATIVI.pdf. Acesso em: 30 mar. 2021.

DANIELLI, R.. A Judicialização da Saúde no Brasil: Do Viés Individualista ao Patamar de Bem Coletivo. 1 reimpr. Belo Horizonte: Fórum, 2018.

DIMOULIS, D.; MARTINS, L. Teoria Geral dos Direitos Fundamentais. São Paulo: Editora Revista dos Tribunais, 2008.

EL KHATIB, Ahmed Sameer. Economía versus epidemiología: un análisis del comercio entre mercados y vidas en tiempos de COVID-19. Contabilidad y Negocios, v. 15, n. 30, p. 62-80, 23 dez. 2020.

FIGUEIREDO, M. F. Direito fundamental à saúde: parâmetros para sua eficácia e efetividade. Porto Alegre: Livraria do Advogado, 2007.

FLUMIAN, M. E. Direito fundamental à saúde: políticas econômicas e sociais de atenção básica e os balizadores da prestação jurisdicional. 2008. Dissertação (Mestrado). Centro Universitário Unitoledo de Araçatuba.

MARRARA, T.; NUNES, L. N. B. Reflexões sobre o controle das políticas de saúde e de medicamentos. In: BLIACHERIENE, Ana Carla; SANTOS, José Sebastião (Org.). Direito à vida e à saúde: impactos orçamentário e judicial. São Paul: Atlas, 2010.

PICARDI, N.. Jurisdição e Processo. Rio de Janeiro: Forense. 2008.

SALAZAR, A. L.; GROU, K. B. A defesa da saúde em juízo. São Paulo: Editora Verbatim, 2009.

SARLET, I. W. Algumas considerações em torno do conteúdo, eficácia e efetividade do direito à saúde na Constituição de 1988. Revista Eletrônica sobre a Reforma do Estado. Salvador, n. 11, set. 2007a. Disponível em:

http://www.egov.ufsc.br/portal/sites/default/files/rere-11-setembro-2007ingo_sarlet_1.pdf. Acesso em: 22 mar 2021.

SARLET, I. W.; FIGUEIREDO, M. F. Reserva do possível, mínimo existencial e direito à saúde: algumas aproximações. DIREITOS FUNDAMENTAIS \& JUSTIÇA No . 2007b. Disponível em: http://dfj.emnuvens.com.br/dfj/article/view/590/73. Acesso em: 05 mar 2021.

SARMENTO, D.. A proteção Judicial dos Direitos Sociais: alguns parâmetros éticos e jurídicos. In: NOVELINO, Marcelo (Org.). Leituras Complementares de Direito

Constitucional: direitos humanos e direitos fundamentais. 4. ed. ampl. rev. atual. São Paulo: JusPodivm, 2010. 
SIEYÈS, Emmanuel Joseph. O que é o Terceiro Estado? Rio de Janeiro: Lumen Iuris, 1988.

SILVA, J. A. da. Curso de Direito constitucional positivo. São Paulo: Malheiros, 2020.

SOUZA, H. A. de; SANTOS, J. S. dos; UETA, Julieta Mieko. A influência da gestão do sistema de saúde na utilização da via judicial para acesso a produtos e serviços. In: Direito à vida e à saúde: impactos orçamentário e judicial[S.l: s.n.], 2010.

TORRES, R. L.. O direito ao mínimo existencial. Rio de Janeiro: Renovar, 2009.

VIANNA, J. R. A. A função social do Poder Judiciário no Estado Democrático de

Direito. In: ANIMA: Revista Eletrônica do Curso de Direito das Faculdades OPET. Curitiba PR - Brasil. Ano IX, nº. 16, jan/jun 2017.

WANG, D. W.. Reserva do possível, mínimo existencial e direito à saúde: algumas aproximações. (Resenha). Revista de Direito Sanitário, São Paulo, v. 10, n. 1, p. 308-318, mar./jul. 2009. 